\title{
A COMPARATIVE STUDY OF ROPIVACAINE AND ROPIVACAINE WITH DEXMEDETOMIDINE AS POSTOPERATIVE ANALGESIA FOR LOWER ABDOMINAL SURGERIES UNDER ULTRASOUND-GUIDED TRANSVERSUS ABDOMINIS PLANE BLOCK
}

\author{
S. Ramesh Kumar1, R. Vasanthageethan², G. Selvaraju ${ }^{3}$ \\ ${ }^{1}$ Assistant Professor, Department of Anaesthesiology, Government Mohan Kumaramangalam Medical College Hospital, Salem. \\ ${ }^{2}$ Assistant Professor, Department of Anaesthesiology, Government Mohan Kumaramangalam Medical College Hospital, Salem. \\ ${ }^{3}$ Senior Resident, Department of Anaesthesiology, Government Mohan Kumaramangalam Medical College Hospital, Salem.
}

\section{ABSTRACT}

\section{BACKGROUND}

Ultrasound-guided Transversus Abdominis Plane block for providing postoperative analgesia for lower abdominal surgeries are performed commonly nowadays. Injection of alpha-2 adrenergic agonist drugs have been suggested for improving the quality of nerve block.

The aim of this study was to compare the efficacy of Ropivacaine and Ropivacaine with Dexmedetomidine in providing postoperative analgesia for lower abdominal surgeries under ultrasound-guided TAP block.

\section{MATERIALS AND METHODS}

This study was done in sixty patients of age group 18 - 60 years under ASA I and II randomly allotted into two groups of thirty each undergoing lower abdominal surgeries. Group A received only Ropivacaine, while Group B received Ropivacaine with Dexmedetomidine.

\section{RESULTS}

Patients in Group B had extended duration of analgesia with minimal sedation.

\section{CONCLUSION}

The study showed that the addition of Dexmedetomidine to Ropivacaine in TAP block extended the duration of analgesia with minimal sedation without significant changes in haemodynamic parameters or complications.

\section{KEYWORDS}

TAP - Transversus Abdominis Plane, VAS - Visual Analogue Scale, BMI - Body Mass Index, SAB - Subarachnoid Block.

HOW TO CITE THIS ARTICLE: Kumar SR, Vasanthageethan R, Selvaraju G. A comparative study of Ropivacaine and Ropivacaine with dexmedetomidine as postoperative analgesia for lower abdominal surgeries under ultrasound-guided transversus abdominis plane block. J. Evolution Med. Dent. Sci. 2017;6(15):1209-1214, DOI: 10.14260/Jemds/2017/263

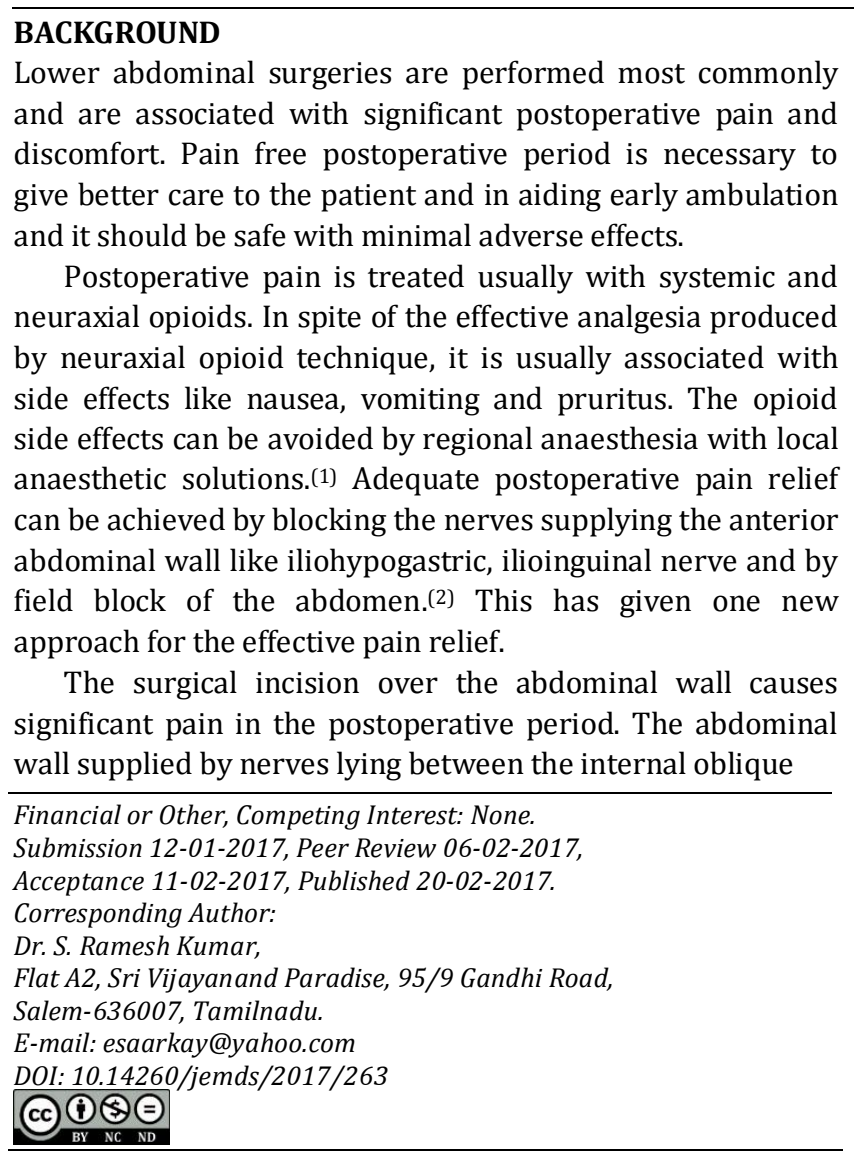
and transversus abdominis muscles can be blocked by injecting local anaesthetic drugs in the transverse abdominal plane in the region of Petit's triangle (TAP Block).(3) Andrew et al(4) in their study had shown the effects of TAP block.

First transversus abdominis plane block was described by Rafi in 2001.(5) McDonell et al(6) described about TAP block in cadavers and humans in 2004. Curley et al,(7) French et al(8) and Carvello et al ${ }^{(9)}$ in their studies have shown the beneficial effects of TAP block in post LSCS patients. Hebbard et al(10) described about the TAP block by using ultrasound-guided technique in 2007. Walter et al(11) in their study showed that the results were better in ultrasound guidance technique with posterior approach. TAP block success depends on injection of local anaesthetic drugs between transversus abdominis and internal oblique muscle where the neurofascial plane lies. There are many techniques for the nerve blocks and among them ultrasound-guided technique seems to be the most reliable. It helps to guide the needle towards the nerves or structures targeted and to see the spread of injected local anaesthetic drugs.(12) The dose of local anaesthetic and opioid requirement is reduced with this technique.

Injection of alpha-2 adrenergic agonist drugs like Clonidine and Dexmedetomidine has been suggested for improving the quality of nerve block. Dexmedetomidine is a selective agonist for alpha-2 receptors with some agonistic property on alpha- 1 receptors as well. The onset time, block 
efficacy and postoperative analgesic duration is prolonged with usage of Dexmedetomidine with local anaesthetic drugs.

\section{Aim of the Study abdominis plane block. \\ MATERIALS AND METHODS \\ Study Type - Interventional. \\ Study Design - Prospective randomised study.}

A comparative study of Ropivacaine and Ropivacaine with Dexmedetomidine as postoperative analgesia for lower abdominal surgeries under ultrasound-guided Transversus

\section{Study Population}

Sixty patients who were posted for lower abdominal surgeries at Govt. Mohan Kumaramangalam Medical College and Hospital, Salem, were taken up for the study.

\section{Case Definition}

Patients of age group 18 - 60 years with ASA I and II undergoing lower abdominal surgeries.

\section{Groups}

Group A - (Contains 30 patients): SAB with Inj. 0.5\% hyperbaric Bupivacaine $15 \mathrm{mg}$, then TAP block with Inj. $0.375 \%$ Ropivacaine $20 \mathrm{~mL}$.

Group B - (Contains 30 patients): SAB with Inj. 0.5\% hyperbaric Bupivacaine $15 \mathrm{mg}$ then TAP block with Inj. $0.375 \%$ Ropivacaine $20 \mathrm{~mL}+$ Dexmedetomidine $0.5 \mathrm{mcg} / \mathrm{kg}$ body wt.

\section{Outcome Measures for this Clinical Trial}

To evaluate the analgesic efficacy of Ropivacaine and Ropivacaine with Dexmedetomidine by using Visual Analogue Scale pain scores in 1, 2, 3, 4, 5, 6, 12 and 24 hrs. after surgery and to evaluate the sedation score of the patient.

\section{Inclusion Criteria}

1. ASA Class I and II patients.

2. 18 to 60 years of age.

\section{Exclusion Criteria}

1. Patient refusal.

2. Patient with known allergic reaction to local anaesthetics.

3. History of bleeding diathesis.

4. Known psychiatric illness.

5. Patients on chronic analgesics.

6. $\mathrm{BMI}>40 \mathrm{~kg} / \mathrm{m}^{2}$.

7. Liver failure and Renal failure.

\section{Probability Sampling}

60 lots were randomised (30 in each group) from the people who were willing to take part in the study. All the patients stand an equal chance of getting into any group. All the patients were aware of the study and informed consent was obtained.

\section{Data Collection}

Age, BMI, duration of surgery, time to regression of sensory block to T10 level, VAS (In 1, 2, 3, 4, 5, 6, 7, 8, 10, 12 and 24 hrs.), heart rate, systolic BP, diastolic $\mathrm{BP}, \mathrm{SpO} 2$, respiratory rate, duration of analgesia and sedation score.

\section{Materials}

1. Ultrasound machine with high frequency transducer probe.

2. Sterile gel, antiseptics.

3. 23-G Quincke spinal needle.

4. Inj. 0.5\% Bupivacaine Heavy.

5. 18-G Tuohy needle.

6. Inj. $0.375 \%$ Ropivacaine.

7. Sterile normal saline.

8. Inj. Dexmedetomidine.

9. $10 \mathrm{~mL}$ and $20 \mathrm{~mL}$ syringes.

10. Swabs, swab holding forceps and sterile towel.

\section{Method of Study}

The Hospital Ethical Committee approval was obtained first with proper explanation and written informed patient consent was obtained. The study was conducted in 60 ASA status I and II patients undergoing lower abdominal surgeries in a prospective, randomised, double-blinded, controlled trial. In the preoperative waiting room, detailed history and physical examination was done. Baseline data like pulse rate, blood pressure, respiratory rate and basic investigations were collected.

Both groups were explained about the procedures (Both SAB and TAP Block) and postoperative followup pattern. The VAS was explained as $0-10 \mathrm{~cm}$ scale reading and patient was asked to tell the number.

Patients were divided randomly and allotted in either Group A ( $=30)$ or Group B ( $=30)$.

The investigator, patients and postoperative care physicians were blinded to group assigned. Common to both groups, an 18-G IV cannula was secured and preloading done with $1000 \mathrm{~mL}$ of crystalloid. Under asepsis, patient in lateral position, subarachnoid block was given with Inj. 0.5\% Bupivacaine $15 \mathrm{mg}$ using 23-G Quincke's spinal needle to all the patients in both groups. Patients were monitored intraoperatively and after the surgical procedure was over patient's sensory level was assessed, and once when the sensory level reached T10 TAP was performed.

Under asepsis, TAP Block was performed. An ultrasoundguided posterior TAP block technique was used to locate the Transverse abdominis plane. Patient was positioned supine; syringe containing local anaesthetic was prepared with asepsis. Syringes either contain Ropivacaine $0.375 \% 20 \mathrm{~mL}$ or Ropivacaine $0.375 \%$ with Dexmedetomidine $0.5 \mathrm{mcg} / \mathrm{kg}$ $20 \mathrm{~mL}$. Investigators were blinded to the injected solution. A high frequency $(10-15 \mathrm{~Hz})$ Ultrasound probe was placed midway between the costal margin and iliac crest along the mid-axillary line. The satisfactory image was aimed to visualise the subcutaneous fat and all the three anterior abdominal wall muscles with peritoneum and intraperitoneal cavity. An 18-G Tuohy needle was inserted anterior to the ultrasound probe. This wide bore needle was used for better visualisation and will not cause much discomfort to the patients, as they were still under residual analgesia from the SAB. With continuous monitoring of needle advancement in the fascial plane between transverse abdominis muscle and internal oblique muscle, a small volume of drug was injected to confirm the correct plane and needle tip and then $20 \mathrm{~mL}$ of prepared solution was injected. Injection was said to be successful when an echo-lucent lensshaped (bi-convex) area come into view between the two 
muscles. After observing closely for signs of toxicity, patients were shifted to postoperative ward.

\section{Total Duration of Analgesia}

The presence and severity of pain assessment was done with visual analogue scale (VAS score 0: no pain and 10: worst pain) in $1,2,3,4,5,6,7,8,10,12$ and 24 hrs. by an investigator blinded to group assigned. Sedation was monitored using Ramsay sedation score. Vital parameters and symptoms and signs of local anaesthetic toxicity and complications were recorded till the VAS score was equal to 4 in the immediate postoperative period after TAP block.

\section{Sedation Score}

Sedation was monitored using six point Ramsay sedation score. The primary end point of the study is when the VAS score reached $=4$.

\section{Rescue Analgesia}

Inj. Tramadol $100 \mathrm{mg}$ IM was used as first rescue analgesia either on demand or when the VAS score was $=4$.

\section{Data Analysis}

In this study, the analgesic efficacy of Ropivacaine and adjuvant Dexmedetomidine in ultrasound-guided Transversus abdominis plane block for lower abdominal surgeries for postoperative pain relief is evaluated. The observation and results were analysed. Data analysis was done with the help of computer using Epidemiological
Information Package (EPI 2010) developed by Centre for Disease Control, Atlanta. Results were considered statistically significant when " $\mathrm{p}$ " value was $=0.05$. In order to ascertain the significance of demographic features, Kruskul Wallis chisquare test was used to test the significance of difference between quantitative variables and Yate's chi square test for qualitative variables. A ' $\mathrm{p}$ ' value less than 0.05 is taken to denote significant relationship.

\section{RESULTS}

\begin{tabular}{|c|c|c|c|c|c|}
\hline Age & N & Mean & SD & T & P \\
\hline Ropivacaine & 30 & 50.77 & 13.95 & & \multirow{2}{*}{0.085} \\
\cline { 1 - 4 } $\begin{array}{c}\text { Ropivacaine with } \\
\text { Dexmedetomidine }\end{array}$ & 30 & 45.00 & 11.43 & 1.75 & 0.085 \\
\cline { 1 - 2 } & Age Distribution \\
\hline
\end{tabular}

\begin{tabular}{|c|c|c|c|c|c|}
\hline \multirow{2}{*}{ Group } & \multicolumn{4}{|c|}{ Sex } & \multirow{2}{*}{ Total } \\
\cline { 2 - 5 } & \multicolumn{2}{|c|}{ Male } & \multicolumn{2}{c|}{ Female } & \\
\cline { 2 - 5 } & $\mathbf{N}$ & $\mathbf{\%}$ & $\mathbf{N}$ & $\mathbf{\%}$ & \\
\hline Ropivacaine & 25 & 83 & 5 & 17 & 30 \\
\hline $\begin{array}{c}\text { Ropivacaine with } \\
\text { Dexmedetomidine }\end{array}$ & 26 & 87 & 4 & 13 & 30 \\
\hline Total Gender Distribution & $\mathbf{5 1}$ & $\mathbf{0 . 8 5}$ & $\mathbf{9}$ & $\mathbf{0 . 1 5}$ & $\mathbf{6 0}$ \\
\hline \multicolumn{7}{|c}{} \\
\hline
\end{tabular}

The two groups were similar with respect to age and gender distribution and the difference was statistically insignificant.

\begin{tabular}{|c|c|c|c|c|c|c|}
\hline & Group & $\mathbf{N}$ & Mean & SD & $\mathbf{T}$ & $\mathbf{P}$ \\
\hline \multirow[b]{2}{*}{ Duration of Analgesia } & Ropivacaine & 30 & 352.17 & 22.88 & \multirow[b]{2}{*}{12.33} & \multirow[b]{2}{*}{$<0.001^{* *}$} \\
\hline & Ropivacaine with Dexmedetomidine & 30 & 482.00 & 52.94 & & \\
\hline \multirow{2}{*}{ Sedation Score } & Ropivacaine & 30 & 2.23 & 0.43 & \multirow{2}{*}{0.29} & \multirow{2}{*}{0.770} \\
\hline & Ropivacaine with Dexmedetomidine & 30 & 2.27 & 0.45 & & \\
\hline \multicolumn{7}{|c|}{ Duration of Analgesia and Sedation Score } \\
\hline
\end{tabular}

The duration of analgesia was significantly increased with 130 mins in Ropivacaine with Dexmedetomidine group, which was statistically significant. Even though the sedation score was more in Ropivacaine with Dexmedetomidine group than plain Ropivacaine group, it was not clinically significant.

\begin{tabular}{|c|c|c|c|c|c|c|}
\hline & Group & $\mathbf{N}$ & Mean & SD & $\mathbf{T}$ & $\mathbf{P}$ \\
\hline \multirow{2}{*}{ VAS Score 5 hrs. } & Ropivacaine & 30 & 4.60 & 0.56 & \multirow{2}{*}{22.64} & \multirow{2}{*}{$<0.001$} \\
\hline & Ropivacaine with Dexmedetomidine & 30 & 0.17 & 0.91 & & \\
\hline \multirow{2}{*}{ VAS Score 6 hrs. } & Ropivacaine & 30 & 4.70 & 0.60 & \multirow{2}{*}{17.07} & \multirow{2}{*}{$<0.001$} \\
\hline & Ropivacaine with Dexmedetomidine & 30 & 0.33 & 1.27 & & \\
\hline \multirow{2}{*}{ VAS Score 12 hrs. } & Ropivacaine & 30 & 4.57 & 0.50 & \multirow{2}{*}{1.69} & \multirow{2}{*}{0.004} \\
\hline & Ropivacaine with Dexmedetomidine & 30 & 4.30 & 0.70 & & \\
\hline \multirow{2}{*}{ VAS Score 24 hrs. } & Ropivacaine & 30 & 4.70 & 0.75 & \multirow{2}{*}{0.933} & \multirow{2}{*}{0.003} \\
\hline & Ropivacaine with Dexmedetomidine & 30 & 4.53 & 0.63 & & \\
\hline
\end{tabular}

The duration of analgesia was significantly increased with 130 mins in Ropivacaine with Dexmedetomidine group

\begin{tabular}{|c|c|c|c|c|c|c|}
\hline & Group & $\mathbf{N}$ & Mean & SD & $\mathbf{T}$ & $\mathbf{p}$ \\
\hline \multirow{2}{*}{ PR0 } & Ropivacaine & 30 & 86.97 & 9.34 & \multirow{2}{*}{0.79} & \multirow{2}{*}{0.430} \\
\hline & Ropivacaine with Dexmedetomidine & 30 & 88.90 & 9.50 & & \\
\hline \multirow{2}{*}{ PR 30 mins } & Ropivacaine & 30 & 86.67 & 8.62 & \multirow{2}{*}{1.31} & \multirow{2}{*}{0.195} \\
\hline & Ropivacaine with Dexmedetomidine & 30 & 89.47 & 7.90 & & \\
\hline \multirow{2}{*}{ PR $1 \mathrm{hr}$. } & Ropivacaine & 30 & 84.43 & 9.29 & \multirow{2}{*}{0.68} & \multirow{2}{*}{0.500} \\
\hline & Ropivacaine with Dexmedetomidine & 30 & 86.03 & 8.95 & & \\
\hline \multirow{2}{*}{ PR 2 hrs. } & Ropivacaine & 30 & 90.23 & 7.70 & \multirow{2}{*}{0.20} & \multirow{2}{*}{0.845} \\
\hline & Ropivacaine with Dexmedetomidine & 30 & 89.83 & 8.05 & & \\
\hline PR 3 hrs. & Ropivacaine & 30 & 85.40 & 8.09 & 0.37 & 0.711 \\
\hline
\end{tabular}




\begin{tabular}{|c|c|c|c|c|c|c|}
\hline & Ropivacaine with Dexmedetomidine & 30 & 84.60 & 8.52 & & \\
\hline \multirow{2}{*}{ PR 4 hrs. } & Ropivacaine & 30 & 86.13 & 9.37 & \multirow{2}{*}{0.28} & \multirow{2}{*}{0.783} \\
\hline & Ropivacaine with Dexmedetomidine & 30 & 86.80 & 9.29 & & \\
\hline \multirow{2}{*}{ PR 5 hrs. } & Ropivacaine & 30 & 84.67 & 8.76 & \multirow{2}{*}{0.46} & \multirow{2}{*}{0.649} \\
\hline & Ropivacaine with Dexmedetomidine & 30 & 85.70 & 8.75 & & \\
\hline \multirow{2}{*}{ PR 6 hrs. } & Ropivacaine & 30 & 86.13 & 9.37 & \multirow{2}{*}{0.39} & \multirow{2}{*}{0.695} \\
\hline & Ropivacaine with Dexmedetomidine & 30 & 87.07 & 9.01 & & \\
\hline \multirow{2}{*}{ PR 12 hrs. } & Ropivacaine & 30 & 84.67 & 8.76 & \multirow{2}{*}{0.62} & \multirow{2}{*}{0.538} \\
\hline & Ropivacaine with Dexmedetomidine & 30 & 86.03 & 8.32 & & \\
\hline \multirow{2}{*}{ PR 24 hrs. } & Ropivacaine & 30 & 88.43 & 8.79 & \multirow{2}{*}{0.13} & \multirow{2}{*}{0.894} \\
\hline & Ropivacaine with Dexmedetomidine & 30 & 88.76 & 9.80 & & \\
\hline
\end{tabular}

Both the groups were comparable on measuring pulse rate and the difference was statistically insignificant.

\begin{tabular}{|c|c|c|c|c|c|c|}
\hline & Group & $\mathbf{N}$ & Mean & SD & $\mathbf{T}$ & $\mathbf{p}$ \\
\hline \multirow{2}{*}{ SBP 0} & Ropivacaine & 30 & 115.57 & 10.41 & \multirow{2}{*}{0.27} & \multirow{2}{*}{0.787} \\
\hline & Ropivacaine with Dexmedetomidine & 30 & 114.83 & 10.53 & & \\
\hline \multirow{2}{*}{ SBP 30 mins } & Ropivacaine & 30 & 113.97 & 11.06 & \multirow{2}{*}{0.20} & \multirow{2}{*}{0.842} \\
\hline & Ropivacaine with Dexmedetomidine & 30 & 114.53 & 10.92 & & \\
\hline \multirow{2}{*}{ SBP $1 \mathrm{hr}$. } & Ropivacaine & 30 & 112.27 & 20.78 & \multirow{2}{*}{0.14} & \multirow{2}{*}{0.892} \\
\hline & Ropivacaine with Dexmedetomidine & 30 & 111.53 & 20.79 & & \\
\hline \multirow{2}{*}{ SBP 2 hrs. } & Ropivacaine & 30 & 111.03 & 10.18 & \multirow{2}{*}{0.73} & \multirow{2}{*}{0.466} \\
\hline & Ropivacaine with Dexmedetomidine & 30 & 112.90 & 9.53 & & \\
\hline \multirow{2}{*}{ SBP 3 hrs. } & Ropivacaine & 30 & 115.13 & 9.25 & \multirow{2}{*}{1.19} & \multirow{2}{*}{0.237} \\
\hline & Ropivacaine with Dexmedetomidine & 30 & 117.63 & 6.78 & & \\
\hline \multirow{2}{*}{ SBP 4 hrs. } & Ropivacaine & 30 & 116.47 & 9.64 & \multirow{2}{*}{1.55} & \multirow{2}{*}{0.127} \\
\hline & Ropivacaine with Dexmedetomidine & 30 & 112.67 & 9.35 & & \\
\hline \multirow{2}{*}{ SBP 5 hrs. } & Ropivacaine & 30 & 118.67 & 9.75 & \multirow{2}{*}{0.48} & \multirow{2}{*}{0.633} \\
\hline & Ropivacaine with Dexmedetomidine & 30 & 117.60 & 7.27 & & \\
\hline \multirow{2}{*}{ SBP 6 hrs. } & Ropivacaine & 30 & 118.67 & 9.75 & \multirow{2}{*}{0.48} & \multirow{2}{*}{0.633} \\
\hline & Ropivacaine with Dexmedetomidine & 30 & 117.60 & 7.27 & & \\
\hline \multirow{2}{*}{ SBP 12 hrs. } & Ropivacaine & 30 & 118.67 & 9.75 & \multirow{2}{*}{0.48} & \multirow{2}{*}{0.633} \\
\hline & Ropivacaine with Dexmedetomidine & 30 & 117.60 & 7.27 & & \\
\hline \multirow{2}{*}{ SBP $24 \mathrm{hrs}$. } & Ropivacaine & 30 & 117.27 & 8.83 & \multirow{2}{*}{0.31} & \multirow{2}{*}{0.757} \\
\hline & Ropivacaine with Dexmedetomidine & 30 & 116.47 & 11.02 & & \\
\hline
\end{tabular}

Both the groups were comparable on measuring Systolic BP and the difference was statistically insignificant.

\begin{tabular}{|c|c|c|c|c|c|c|}
\hline & Group & $\mathbf{N}$ & Mean & SD & $\mathbf{t}$ & $\mathbf{P}$ \\
\hline \multirow{2}{*}{ DBP 0} & Ropivacaine & 30 & 83.37 & 8.43 & \multirow{2}{*}{4.96} & \multirow{2}{*}{$<0.001^{* *}$} \\
\hline & Ropivacaine with Dexmedetomidine & 30 & 101.83 & 18.55 & & \\
\hline \multirow{2}{*}{ DBP 30 mins } & Ropivacaine & 30 & 83.93 & 9.42 & \multirow{2}{*}{0.83} & \multirow{2}{*}{0.411} \\
\hline & Ropivacaine with Dexmedetomidine & 30 & 85.77 & 7.65 & & \\
\hline \multirow{2}{*}{ DBP 1 hrs. } & Ropivacaine & 30 & 80.30 & 9.35 & \multirow{2}{*}{1.96} & \multirow{2}{*}{0.054} \\
\hline & Ropivacaine with Dexmedetomidine & 30 & 84.90 & 8.78 & & \\
\hline \multirow{2}{*}{ DBP 2 hrs. } & Ropivacaine & 30 & 83.80 & 7.25 & \multirow{2}{*}{0.33} & \multirow{2}{*}{0.739} \\
\hline & Ropivacaine with Dexmedetomidine & 30 & 83.10 & 8.88 & & \\
\hline \multirow{2}{*}{ DBP 3 hrs. } & Ropivacaine & 30 & 85.37 & 7.18 & \multirow{2}{*}{1.86} & \multirow{2}{*}{0.068} \\
\hline & Ropivacaine with Dexmedetomidine & 30 & 81.90 & 7.28 & & \\
\hline \multirow{2}{*}{ DBP 4 hrs. } & Ropivacaine & 30 & 84.20 & 8.41 & \multirow{2}{*}{0.05} & \multirow{2}{*}{0.960} \\
\hline & Ropivacaine with Dexmedetomidine & 30 & 84.30 & 7.04 & & \\
\hline \multirow{2}{*}{ DBP 5 hrs. } & Ropivacaine & 30 & 84.47 & 8.66 & \multirow{2}{*}{0.11} & \multirow{2}{*}{0.911} \\
\hline & Ropivacaine with Dexmedetomidine & 30 & 84.23 & 7.39 & & \\
\hline \multirow{2}{*}{ DBP 6 hrs. } & Ropivacaine & 30 & 84.20 & 8.41 & \multirow{2}{*}{0.02} & \multirow{2}{*}{0.987} \\
\hline & Ropivacaine with Dexmedetomidine & 30 & 84.23 & 7.39 & & \\
\hline \multirow{2}{*}{ DBP 12 hrs. } & Ropivacaine & 30 & 84.20 & 7.92 & \multirow{2}{*}{0.18} & \multirow{2}{*}{0.860} \\
\hline & Ropivacaine with Dexmedetomidine & 30 & 84.59 & 8.77 & & \\
\hline \multirow{2}{*}{ DBP 24 hrs. } & Ropivacaine & 30 & 84.20 & 7.92 & \multirow{2}{*}{0.23} & \multirow{2}{*}{0.816} \\
\hline & Ropivacaine with Dexmedetomidine & 30 & 84.70 & 8.64 & & \\
\hline & & & $B P$ & & & \\
\hline
\end{tabular}

Both the groups were comparable Diastolic BP and the difference is statistically insignificant. 


\section{DISCUSSION}

Adequate pain relief has been shown to reduce stress postoperatively leading to a quick recovery, early mobilisation and reduced morbidity in the postoperative period. It has been shown that local anaesthetic used in various techniques reduces pain and analgesic requirements, which can improve the quality of postoperative recovery. The efficacy of TAP block by using local anaesthetics is proved in many studies. McDonnell J G(6) et al in their study has proved the beneficial effect of Ropivacaine in TAP block for post caesarean section patients.

In order to increase the duration of block, Dexmedetomidine has been used as an adjuvant to local anaesthetics in different regional techniques. So Dexmedetomidine as an adjuvant in TAP block is expected to prolong the duration of block, thereby achieving a good postoperative analgesia.

D. Belavy and J. Cowlishaw(13) et al has shown the efficacy of ultrasound-guided TAP blocks in post caesarean section patients. So this study was done to evaluate the postoperative analgesic efficacy of Ropivacaine alone or in combination with Dexmedetomidine in ultrasound-guided TAP block. In this study, the local anaesthetics were deposited in the correct plane under ultrasound guidance. Rachana Gandhi et al(14) have shown in their study that Dexmedetomidine added to local anaesthetics prolongs the duration of analgesia.

In this study, $20 \mathrm{~mL}$ of Inj. $0.375 \%$ Ropivacaine or Inj. $0.375 \%$ Ropivacaine with Dexmedetomidine $0.5 \mathrm{mcg} / \mathrm{kg}$ for ultrasound-guided TAP block was used, which is comparable to many studies.

Tramadol was selected for rescue analgesia, as several studies have confirmed that a single dose of intramuscular Tramadol 50 - $100 \mathrm{mg}$ can provide effective analgesia in postoperative patients.

Ultrasound-guided TAP block has been shown to provide adequate analgesia to the skin and anterior abdominal wall musculature in patients undergoing lower abdominal surgeries. All patients in both groups breathed deeply, coughed freely, moved without limitation and showed good satisfaction. The Ropivacaine with Dexmedetomidine group showed increased duration of analgesia with minimal sedation.

\section{Duration of Postoperative Analgesia}

In this study, results had demonstrated that postoperative ultrasound-guided TAP block reduced VAS score in both the groups. In Group A (0.375\% Ropivacaine alone) the VAS score was almost zero in the first 4 hours, while in Group B the VAS score was zero for about 6 hours which itself explains the effectiveness of TAP block.

In this study, the mean time to reach VAS score of $=4$ was 482 minutes in Ropivacaine with Dexmedetomidine 0.5 $\mathrm{mcg} / \mathrm{kg}$ group when compared with 352 minutes in the $0.375 \%$ Ropivacaine. The difference of 130 minutes with $\mathrm{P}$ value less than 0.001 was very significant statistically.

The reason for extended analgesic duration after TAP blockade may be due to the relatively reduced vascularisation and slower drug clearance from transversus abdominis plane and may be due to avoidance of central sensitisation by giving TAP block postoperatively. The prolonged action of Dexmedetomidine may be produced by the membrane hyperpolarisation due to opening of the potassium channels, which increases the sodium channel blocking property of local anaesthetic. When added to local anaesthetic, it enhances the quality and reduces the time of onset of block.

\section{Sedation}

The mean sedation score of 2.27 was obtained in Ropivacaine with Dexmedetomidine group compared to 2.23 obtained in Ropivacaine group. Even though the sedation score was more in Ropivacaine with Dexmedetomidine group than plain Ropivacaine group, it is not clinically significant. Dexmedetomidine added to Ropivacaine for prolonging analgesic duration also had minimal sedative effect, but arousable sleep. Thus, TAP block as a component of multimodal analgesia has significantly increased the total postoperative analgesia and those who received Dexmedetomidine in addition to Ropivacaine had prolonged duration of analgesia with minimal sedation without any complications.

\section{Haemodynamic Stability}

Haemodynamic stability in terms of changes in pulse rate, oxygen saturation and blood pressure was compared in both groups and there were no significant difference between them.

\section{Complications}

In this study, the incidence of postoperative nausea and vomiting was very much reduced in both groups. This is similar to study conducted by Jumana M Baaj et al,(15) where they reported reduced incidence of postoperative nausea and vomiting. Complications like peritoneal and visceral punctures related to TAP block were not encountered in this study. Thorough familiarity with anatomy, safe monitoring and injection technique, knowledge of local anaesthetic pharmacology and toxicity would prevent the possibility of complications and the technique of TAP block is further simplified by proper knowledge and correct use of ultrasound. These precautions will prevent major complications with TAP block. By using ultrasonography, real time needle position can be confirmed and is a promising approach that should further decrease the risk of visceral injury complication.

\section{CONCLUSION}

Ultrasound-guided TAP block as a technique for providing postoperative analgesia is highly effective for lower abdominal surgeries. The addition of Dexmedetomidine to Ropivacaine in TAP block extended the duration of analgesia with minimal sedation when compared to plain Ropivacaine without significant changes in haemodynamic parameters or complications. Ultrasound-guided TAP block is easier to perform and provides reliable and effective analgesia.

\section{REFERENCES}

[1] Rushman G. Lee's synopsis of anaesthesia. Chapter on Techniques of Regional Analgesia. 10th edn. 1987:63740.

[2] Rozen WM, Tran TM, Ashton MW, et al. Refining the course of the thoracolumbar nerves: a new understanding of the innervation of the anterior abdominal wall. Clinical Anatomy 2008;21(4):325-33. 
[3] Shibata Y, Sato Y, Fujiwara Y, eta l. Transversus abdominis plane block. Anesth Analg 2007;105(3):883.

[4] Mark JY, Andrew WG, Vicki EM, et al. Clinical Implications of the transversus abdominis plane block in adults. Anesthesia Research and Practice Article ID 731645, 2012:2012. p. 11.

[5] Rafi AN. Abdominal field block: a new approach via the lumbar triangle. Anaesthesia 2001;56(10):1024-6.

[6] McDonnell JG, O'Donnell B, Curley G, et al. The analgesic efficacy of transverses abdominis plane block after abdominal surgery: a prospective randomized controlled trial. Anesth \& Analg 2007;104(1):193-7.

[7] McDonnel JG, Curley G, Carney J, et al. The analgesic efficacy of transverse abdominis plane block after caesarean delivery: a randomized controlled trial. Anaesthesia \& Analgesia 2008;106(1):186-91.

[8] French JL, McCullough J, Bachra P, et al. Transversus abdominis plane block for analgesia after Caesarean section in a patient with an intracranial lesion. International Journal of Obstetric Anesthesia 2009;18(1):52-4.

[9] Randall IM, Costello J, Carvalho JC. Transverse abdominis plane block in a patient with debilitating pain from an abdominal wall hematoma following Cesarean delivery. Anaesthesia \& Analgesia 2008;106(6):1928.
[10] Hebbard P, Fujiwara Y, Shibata Y, et al. Ultrasoundguided transversus abdominis plane (TAP) block. Anaesthesia and Intensive Care 2007;35(4):616-7.

[11] Walter EJ, Smith P, Albertyn R, et al. Ultrasound imaging for transversus abdominis blocks. Anaesthesia 2008;63(2):211.

[12] Tran TM, Ivanusic JJ, Hebbard P, et al. Determination of spread of injectate after ultrasound-guided transversus abdominis plane block: a cadaveric study. BJA 2009;102(1):123-7.

[13] Belavy D, Cowlishaw PJ, Howes M, et al. Ultrasoundguided transversus abdominis plane block for analgesia after Caesarean delivery. BJA 2009;103(5):726-30.

[14] Gandhi R, Shah A, Patel I. Use of Dexmedetomidine along with Bupivacaine for brachial plexus block. National journal of medical research. National J Med Res 2012;2(1):67-9.

[15] Baaj JM, Alsatli RA, Majaj HA, et al. Efficacy of ultrasound-guided transversus abdominis plane (TAP) block for postcesarean section delivery analgesia--a double-blind, placebo-controlled, randomized study. Middle East Journal of Anaesthesiology 2010: 20 (6):821-6. 